\title{
Evaluation of the pathologic results of prostate biopsies in terms of age, Gleason score and PSA level: Our experience and review of the literature
}

\author{
Selcuk Sarkkaya ${ }^{1}$, Mustafa Resorlu ${ }^{2}$, Ural Oguz $^{3}$, Mustafa Yordam $^{1}$, Omer Faruk Bozkurt $^{1}$, Ali Unsal $^{1}$ \\ ${ }^{1}$ Keçioren Training and Research Hospital, Departmant of Urology, Ankara, Turkey; \\ ${ }^{2}$ Canakkale Onsekiz Mart University, Faculty of Medicine, Departmant of Radiology, Canakkale, Turkey; \\ ${ }^{3}$ Giresun University, Faculty of Medicine, Departmant of Urology, Giresun, Turkey.
}

\begin{abstract}
Summary Objective: To evaluate the pathologic and clinic results of our large series of transrectal prostate biopsies in relation to Gleason score, age and PSA level.

Materials and Methods: We reviewed the pathologic results of transrectal prostate biopsies performed because of high PSA levels and abnormal digital rectal examination findings between January 2008 and February 2012. Results: The pathologic result of 835 prostate biopsies was benign in $82.2 \%$ and malign in $17.8 \%$. Furthermore in $3.7 \%$ high grade PIN (Prostatic Intraepitelial Neoplasia) or ASAP (Atypical Small Acinar Proliferation) was shown. In the interval of total PSA values between 4 and $10 \mathrm{ng} / \mathrm{dl}$, that is thw so-called grey zone, cancer detection rate was $12.4 \%$. There was a significant relationship between cancer detection and cancer stage at all high levels of PSA also in the grey zone. The most common Gleason score observed was $3+3$ wirh a rate of $7.4 \%$ whereas the second most commonly observed scare was $3+4$ with a rate of $2.5 \%$. In the patients with abnormal digital rectal examination findings but normal PSA levels according to age the cancer detection rate was $8.7 \%$, in patients with only high PSA levels the rate was $41.2 \%$ and in the patients with both high PSA levels and abnormal digital rectal examination findings. the rate was $49.3 \%$.

Conclusion: Our study underlines the relationship between age, PSA level and pathologic stage of prostate cancer and also the importance of digital rectal examination.
\end{abstract}

KEY WORDS: Prostate biopsy; Gleason score; Prostate specific antigen.

Submitted 20 September 2014; Accepted 30 November 2014

\section{INTRODUCTION}

Prostate cancer, is the most common cancer observed in men and when deaths due to cancer are considered, prostate cancer ranks second after the lung cancer $(1,2)$. In 2008, 340.000 patients were diagnosed with prostate cancer and over 70.000 deaths were reported due to prostate cancer in European Union countries (3). Early diagnosis of prostate cancer is important as it gives direction to the treatment improving long-term survival (4). Serum PSA level is the most commonly examination used to screen prostate cancer (5).

Prostate biopsy, is the main method for the diagnosis of prostate cancer and higher PSA levels and abnormal digital rectal examination findings are the indications of prostate biopsy $(4,6)$. In the United States of America it is reported that over 1 million prostate biopsies are performed annually (3). Pain, infection and hemorrage are some of the complications of transrectal ultrasonography guided prostate biopsy (6). Gleason score of prostate cancer is used for determining treatment and follow-up modalities $(7,8)$. In this study, we reviewed the pathologic results of prostate biopsies and their relationships with Gleason score, age and PSA level.

\section{Materials AND MEthods}

The results of prostate biopsy performed between January 2008 and February 2012 were reviewed retrospectively. The indications to prostate biopsy were higher PSA levels according to age and abnormal digital rectal examination findings. In our clinic, transrectal ultrasonography guided prostate biopsies were performed for the patients under the age of 50 whewn PSA level was over $2.5 \mathrm{ng} / \mathrm{dl}$, for the patients with age between 50 and 60 when PSA was over $3.5 \mathrm{ng} / \mathrm{dl}$ and for the patients over the age of 60 when PSA level was over $4 \mathrm{ng} / \mathrm{dl}$. Biopsies were also performed for the patients with abnormal digital rectal examination findings regardless of PSA level. After digital rectal examination, biopsies were performed in the left lateral decubitus position. Four ml lidocaine (2\%) or prilocaine (2\%) were used for local anesthesia. Diposable or re-usable guides and 18-gauge biopsy needles were used for the biopsies. Biopsies were performed taking 12 cores ( 6 for right lobe, 6 for left lobe). Detailed consent forms were obtained from the patients who were given detailed information before the biopsy procedure. After the procedure the patients were directed to the uro-oncology polyclinic with the results of biopsies and treatment modalities were decided according to the results. 


\section{RESULTS}

The results of 835 prostate biopsies showed 656 benign findings (78.5\%), 4 Gleason $2+3$ adenocarcinomas (adenoca) (0.5\%), 1 Gleason 3+2 adenoca (0.1\%), 61 Gleason $3+3$ adenoca (7.4\%), 21 Gleason $3+4$ adenoca (2.5\%), 14 Gleason $4+3$ adenoca (1.7\%), 16 Gleason $4+4$ adenoca (1.9\%), 1 Gleason 5+3 adenoca (0.1\%), 20 Gleason 4+5 adenoca (2.5\%), 6 Gleason $5+4$ adenoca $(0.7 \%)$ and 4 Gleason $5+5$ adenoca (0.4\%). Finally High Grade PIN or ASAP were reported in 31 patients (3.7\%) (Table 1). Prostate cancer detection rate was $17.8 \%$ in our prostate biopsy series. There was a significant relationship between higher PSA levels and cancer detection and cancer stage In the interval of total PSA values between 4 and $10 \mathrm{ng} / \mathrm{dl}$, that is the so-called grey zone, cancer detection rate was $12.4 \%$. When the pathologic results were reviewed by the range of serum PSA

levels, in patients with benign prostatic hyperplasia (BPH) PSA level was $<4 \mathrm{ng} / \mathrm{dl}$ in $9.3 \%, 4-10 \mathrm{ng} / \mathrm{ml}$ in $66.8 \%$ and $>10$ $\mathrm{ng} / \mathrm{dl}$ in $23.9 \%$ of the patients whereas in patients with adenocarcinoma PSA level was < 4 $\mathrm{ng} / \mathrm{dl}$ in 4\%, 4-10 ng/dl in $49.3 \%$ and $>10 \mathrm{ng} / \mathrm{dl}$. in $52 \%$. When pathologic data of the patients

\section{Table 1. The distribution} of pathologic results and Gleason scores of the prostate biopsies.

\begin{tabular}{|l|c|c|}
\hline Pathologic result & Number & Percentage \\
\hline Benign & 656 & $\% 78.5$ \\
\hline $2+3$ Adenoca & 4 & $\% 0,5$ \\
\hline $3+2$ Adenoca & 1 & $\% 0,1$ \\
\hline $3+3$ Adenoca & 61 & $\% 7,4$ \\
\hline $3+4$ Adenoca & 21 & $\% 2,5$ \\
\hline $4+3$ Adenoca & 14 & $\% 1,7$ \\
\hline $4+4$ Adenoca & 16 & $\% 1,9$ \\
\hline $5+3$ Adenoca & 1 & $\% 0,1$ \\
\hline $4+5$ Adenoca & 20 & $\% 2,5$ \\
\hline $5+4$ Adenoca & 6 & $\% 0,7$ \\
\hline $5+5$ Adenoca & 4 & $\% 0,4$ \\
\hline Asap/High Pin & 31 & $\% 3.7$ \\
\hline Total & 835 & $\% 100$ \\
\hline
\end{tabular}

Table 2. The distibution of the patients according to pathologic results and relationship between pathologic results, DRE findings and PSA levels.

\begin{tabular}{|l|c|c|c|c|}
\hline $\begin{array}{l}\text { Pathologic } \\
\text { result }\end{array}$ & $\begin{array}{c}\text { Number } \\
\text { of patients }\end{array}$ & $\begin{array}{c}\text { Abnormal } \\
\text { DRE } \\
\text { findings }\end{array}$ & $\begin{array}{c}\text { High PSA } \\
\text { level according } \\
\text { to age }\end{array}$ & $\begin{array}{c}\text { Abnormal } \\
\text { DRE (+) } \\
\text { High PSA levels }\end{array}$ \\
\hline 2+3 Adenoca & 4 & 3 & 3 & 2 \\
\hline $3+2$ Adenoca & 1 & 1 & 1 & 1 \\
\hline $3+3$ Adenoca & 61 & 30 & 54 & 24 \\
\hline 3+4 Adenoca & 21 & 10 & 19 & 8 \\
\hline $4+3$ Adenoca & 14 & 8 & 14 & 8 \\
\hline $4+4$ Adenoca & 16 & 11 & 15 & 10 \\
\hline 5+3 Adenoca & 1 & 1 & 1 & 1 \\
\hline $4+5$ Adenoca & 20 & 14 & 17 & 11 \\
\hline $5+4$ Adenoca & 6 & 6 & 6 & 6 \\
\hline 5+5 Adenoca & 4 & 2 & 4 & 2 \\
\hline Total & 148 & $86(\% 58.1)$ & $134(\% 90.5)$ & $73(\% 49.3)$ \\
\hline
\end{tabular}

Table 3. The age distribution of PSA levels.

\begin{tabular}{|cc|c|c|c|c|}
\hline Age & & $\mathbf{4 0 - 5 0}$ & $\mathbf{5 0 - 6 0}$ & $\mathbf{6 0 - 7 0}$ & $\mathbf{7 0}$ \\
\hline PSA & $0-4 \mathrm{ng} / \mathrm{dL}$ & 5 & 19 & 23 & 10 \\
& $4-10 \mathrm{ng} / \mathrm{dL}$ & 26 & 112 & 161 & 130 \\
& $>10 \mathrm{ng} / \mathrm{dL}$ & 9 & 26 & 113 & 101 \\
\hline Total & 40 & 157 & 397 & 241 \\
\hline
\end{tabular}

with adenocarcinoma were examined, Gleason score was higher than 7 in 33\% of the patients with PSA level $<4$ $\mathrm{ng} / \mathrm{dl}$, in $13.8 \%$ of the patients with PSA level $4-10 \mathrm{ng} / \mathrm{dl}$ and in $46.7 \%$ of the patients with PSA level > $10 \mathrm{ng} / \mathrm{dl}$ (Table 2). When the digital rectal examination findings (DRE) were reviewed, in $71 \%$ of the patients with $\mathrm{BPH}$ DRE findings were normal and in 29\% were abnormal, whereas in $41.9 \%$ of the patients with adenocarcinoma digital rectal examination findings were normal and in 58.1\% abnormal $(p<0.005)$. Adenocarcinoma detection rate was $8.7 \%$ in the patients with normal PSA levels but abnormal DRE findings, $41.2 \%$ in the patients with normal DRE findings but higher PSA levels and $49.3 \%$ in the patients with both higher PSA levels and abnormal DRE findings. Furthermore, cancer was diagnosed in $7.5 \%$ of the patients under the age of $50,14.4 \%$ of the patients between the age of 50 and $60,27 \%$ of the patients over the age of 70 . Gleason score was higher than 7 in $2.5 \%$ of the patients under the age of 50 , in $3.7 \%$ of the patients with age between 50 and 70 , in $10.3 \%$ of the patients over the age of $70(\mathrm{p}<0.05)$ (Table 3$)$.

\section{Discussion}

Transrectal ultrasonography guided prostate biopsy is the main method used for diagnosing prostate cancer. 9 The pathological results of $82.2 \%$ of prostate biopsies were reported as benign and in $66.8 \%$ of the cases with benign pathological results, PSA levels before biopsy procedure were between 4 and $10 \mathrm{ng} / \mathrm{dl}$. On the other hand, according to the literature reviewing the two indications to prostate biopsy, digital rectal examination is considered a subjective parameter (10).

There are several studies about pathologic results of prostate biopsies performed because of high PSA level and abnormal DRE findings. According to the results of Ojewola et al. The total average cancer detection rate was $44 \%$ and more specifically in presence of high PSA level with normal DRE finding the rate was 30\%, in presence of normal PSA level and abnormal DRE finding the rate was $17 \%$ and in presence of both high PSA level and abnormal DRE finding the rate was 62\% (11). In the study of Shim et al. (12) the patients were divided in two groups: 721 patients with normal DRE findings and 192 patients with abnormal DRE findings. Prostate cancer detection rate was higher in the group with abnormal DRE findings but the result was not significant in the patients that had PSA levels between 2.5 and $3.9 \mathrm{ng} / \mathrm{dl}$ and also in the patients with age between 45 and 59 (12). In another study of Thompson et al, including 2950 patients, cancer detection rate was $6.6 \%$ for the patients with PSA level $<0.5 \mathrm{ng} / \mathrm{dl}, 10.1 \%$ for the patients with PSA level between 0.6 and $1 \mathrm{ng} / \mathrm{dl}, 17 \%$ for patients with PSA level between 1.1 and $2.0 \mathrm{ng} / \mathrm{dl}, 23.9 \%$ for patients with PSA level between 2.1 and $3.0 \mathrm{ng} / \mathrm{dl}$ and $26.9 \%$ for patients with PSA level between 3.1 and $4 \mathrm{ng} / \mathrm{dl}$. The result of this study is important as it shows that prostate cancer would be detected also at lower PSA levels (13). Another study by Catalona et al. (14) about biopsies performed only for abnormal digital rectal findings demonstrated a cancer detection rate of $0 \%$. This rate was $6 \%$ for the study by Brawer et al. (15) and 17\% for another 
study by Mettlin et al. (16) The cancer detection rate of the biopsies performed only for high PSA levels was 16\% in the study by Catalona et al. (14) and 19\% for the study by Brawer et al. (15) The review of the pathologic results of the biopsies performed for the presence of both high PSA levels and abnormal DRE findings showed a cancer detection rate of $33 \%$ in the study by Catalona et al. (14), $16 \%$ in the study by Brawer et al. (15), and 38\% in the study by Mettlin et al. (16). In our study, prostate cancer detection rate was $8.7 \%$ for the patients with normal PSA level but abnormal DRE finding, 41.2\% for the patients with high PSA level and normal DRE and $49.3 \%$ for the patients with both high PSA level and abnormal DRE finding. When we look at the results of our study; the rate for the patients with only abnormal DRE finding is consistent with the literature, but the rates for the patients with only high PSA level or with both two indications, are higher than the rates of literature. The rate in presence of two indications was higher than in presence of only one of the indications. This results shows the importance of DRE altough it is a subjective parameter. Pain, hemorrhage and infection are some of the complications of prostate biopsy as it is an invasive procedure and the rate of temporary bacteriemia is $70 \%$ and the rate of bacteriuria is $53 \%(6,17,18)$. According to our previous observations, there was a significant relationship between presence of prostate cancer and risk of bleeding complication after prostate biopsies (19). Furthermore the bleeding complication was observed at higher rates for the patients with higher Gleason scores (19).

Serum PSA level and digital rectal examination are important parameters for the diagnosis and the choice of the method of treatment of prostate cancer. The cancer detection rates are higher when are present both high PSA levels according to age and abnormal digital rectal examination findings. Other results of our study that are consistent with the literature, are the increase of PSA levels with age and the increase of Gleason score with age. There are several limitations about our study and the most important is that the free/total PSA ratio was not evaluated for the patiens with the PSA level between 4 and 10 $\mathrm{ng} / \mathrm{dl}$. In fact free PSA values for some patients were not found and accordingly this parameter was excluded from the analysis. Another important limitation was that the analysis was not extended to PSA levels in the follow-up and to re-biopsy requirements for the patients with normal pathologic results. Despite all these, we think that the results of this study are relevant as they show the relationship between age, PSA level and pathologic stage and also the importance of digital rectal examination.

\section{References}

1. Alptekin A, Ozgok IY, Kilciler M, et al. Our results of transrectal ultrasonography guided prostate biopsies. Turkish Journal of Urology. 1998; 24:140-144.

2. Jemal A, Siegel R, Ward E, et al. Cancer Statistics. Cancer J Clin. 2008; 58:71-96.

3. Carignan A, Roussy JF, Lapointe V, et al. Increasing Risk Of Infectious Complications After Transrectal Ultrasound-Guided Prostate Biopsies: Time To Reassess Antimicrobial Prophylaxis? Eur Urol. 2012; 62:453-459.
4. Tuygun C, Demirel F, Imamoglu A, et al. Comparison of two different prediction systems for calculating the prostate cancer risk before prostate biyopsy. International Haematology-Oncology Journal. 2009; 2:75-81.

5. Ozden E, Inal T, Kupeli S, et al. The diagnostic value of transrectal ultrasonography for detecting the prostate cancer of the patients that have PSA level of $<4 \mathrm{ng} / \mathrm{ml}$. Turkish Journal of Urology. 2004; 30:155-159.

6. Erturhan S, Seckiner I, Yagci F, et al. Antibiotic prophlaxis for transrectal ultrasonography guided prostate biopsy: the comparison of two different antibiotics. Turkish Journal of Urology. 2007; 33:487-490.

7. Bostwick DG. Grading Prostate Cancer. Am J Clin Pathol. 1994; 102:38-56.

8. Gleason DF. Classification Of Prostatic Carcinoma. Cancer Chemoter Rep. 1966; 50:125-8.

9. Akyol I, Ates F, Adayener C, et al. The effects of age, prostate volume and number of cores on pain score for transrectal ultrasonography guided protate biopsy. Turkish Journal of Urology. 2008; 34:22-26.

10. Kurtulus F, Fazlioglu A, Evirgen M, et al. The accuracy of digital rectal examination, prostate spesific antigen, transrectal ultrasonography, PSA density, free/total PSA ratio for the diagnose of prostate cancer. Turkish Journal of Urology. 2004; 30:40-44.

11. Ojewola RW, Tijani KH, Jeje EA, et al. An evaluation of usefulness of prostate spesific antigen and digital rectal examination in the diagnosis of prostate cancer in an unscreened population:experience in an nigerian teaching hospital. West Afr J Med. 2013; 32:8-13.

12. Shim HB, Lee SE, Park HK, Ku JH. Digital rectal examination as a prostate cancer-screening method in a country with a low incidence of prostate cancer. Prostate Cancer and Prostatic Diseases. 2007; 10:250-255.

13. Thompson IM, Pauler DK, Goodman PJ, et al. Prevalence of prostate cancer among men with a prostate-specific antigen level $\leq$ $4.0 \mathrm{ng}$ per milliliter. N Engl J Med. 2004; 350:2239-46.

14. Catalona W, Smith D, Ratcliff T, et al. Measurement of prostate specific antigen in serum as a screening test for prostate cancer. $\mathrm{N}$ Engl J Med. 1991; 324:1156-1161.

15. Brawer MK, Aramburu EAG, Chen GL, et al. The inability of PSA index to enhance the predictive value of PSA in the diagnosis of prostatic carcinoma. J Urol. 1993; 150:369-373.

16. Mettlin C, Lee F, Drago J, et al. The American Cancer Society National Prostate Cancer Detection Project Finding on the detection of early prostate cancer in 2425 Men. Cancer. 1991; 67:2949-2958.

17. Ruebush TK, McConville JH, Calia FM. A Double-blind study of trimetoprim-sulfamethoxazole prophylaxis in patients having transrectal needle biopsy of the prostate. J Urol. 1979; 122:492-494.

18. Melekos MD. Eficacy of prophylactic antimicrobial regimens in preventing infectious complications after transrectal biopsy of the prostate. Int Urol Nephrol. 1990; 22:257-262.

19. Oguz U, Resorlu B, Bayindir M, Unsal A. Does existance of prostate cancer increase the risk of bleeding as a complication of transrectal ultrasonography guided prostate needle biopsies? Turkish Clinics J Urology. 2012; 3:41-5.

\section{Correspondence}

Selcuk Sarkaya, MD - Mustafa Yordam, MD

Omer Faruk Bozkurt, MD - Ali Unsal, MD

Keçioren Training and Research Hospital, Departmant of Urology, Ankara, Turkey

Mustafa Resorlu,MD - mustafaresorlu77@gmail.com

Canakkale Onsekiz Mart University, Faculty of Medicine, Departmant

of Radiology, Terzioglu Yerleskesi, Barbaros Mh, 17100, Canakkale

Ural Oguz, MD

Giresun University, Faculty of Medicine, Departmant of Urology, Giresun, Turkey 